\title{
Development of a Distributed System for Central Exchange of Student Records in Tertiary Institutions
}

\author{
Jimoh, R. G. \\ Dept. of Computer Science, \\ University of llorin, \\ Ilorin, Nigeria
}

\author{
Abduljeleel Kehinde Shittu \\ School of Computing, \\ Universiti Utara Malaysia (UUM), \\ Malaysia
}

\author{
Salman, I. R. \\ Dept. of Computer Science, \\ Federal Polytechnic, Offa, \\ Kwara State, Nigeria
}

\author{
Eniakuomehin, A. Olutoyin \\ Department of Computer Science, Lagos State \\ University, Lagos, Nigeria
}

\begin{abstract}
This paper presents a distributed system for central exchange of student records in tertiary institutions. A distributed system consists of loosely coupled sites that share no physical components, communicate with one another through various communication media such as high-speed network or telephone lines having a substantial degree of mutual independence. Building distributed Database systems enhance sharing of data, autonomy and continuity of operation. The proposed system is web-based using Extensible Mark-up Language (XML), php and mysql database that ensure the realization of institution-specific requirements and needs. With this system, existing problems of managing student's record in the university will be a thing of the past.
\end{abstract}

\section{General Terms}

Distributed System, Central Record Exchange

\section{Keywords}

Distributed System, Central Exchange, Student's Records, Database, XML

\section{Introduction}

No doubt, surviving in the emerging knowledge-driven society (K-Society) requires efficient and reliable knowledge management strategies. This will allow every stakeholder in this type of society to have real time access to information useful capable of guiding various decisions.

The major opportunity brought by internetworking is ubiquitous nature of doing things. Record exchange and management find no exception in this regard, records should be easily accessible, portable, flexible and easily transferred, but in most of our educational institutions, tertiary inclusive this is not the case as records are still manually operated upon. This manual process of exchanging records is complex, problematic and risk prone [3] [5] [7] [8]. Efficient management of records will support smooth access to necessary information [4] [16] [19] [20]. This will eventually haste the decision making process.
Student records consist of vital, valuable and confidential information, which are like the life-blood of the student. In the process of exchange some information might be lost, handled carelessly, tampered with and thus become insecure, thereby placing the student records in hazardous state [3] [7] [8].

To this end, adoption of distributed system for exchange of student records is deemed worthy in order to simplify the procedure of complex student records processing, reduce the risk involved in transporting them and given access only to authorized users [15].

With the increasing population of students in virtually all Nigerian universities, managing records of these students then becomes a serious concern so as to achieve smooth running of the university [11]. The following are few of the student's records that require management:

- Enrolment, admission and pupil information

- Assessment records and reports

- Transfer advice

- School leaver statement / student achievement record

- Records of absences

- Leaving details (forwarding addresses / occupation etc)

- Medical and family information

- Student information card

- Work experience records

- Discipline records

The availability of Database Management System (DBMS) makes it possible to tackle many problems associated with sophisticated databases. The kind of data structure created within the database and the extent of the relationships among them play a powerful role in determining the power of a DBMS [17]. Therefore database modeling and design becomes a crucial activity in the database environment. Good modules yield good database designs serving as the basis for a good application. Conversely good applications cannot be built from a bad database design. 


\section{Problem Definition}

Manual student records processing are faced with the following problems [3] [5] [7] [8] [10] [18]:

1. Insecurity: Not every user should be able to have access to student records, but enforcing such security constraints in manual processing is difficult.

2. Access Difficulty: Obtaining information about a student is a rigorous task and time consuming in a manual system.

3. Data isolation: Because data are scattered in various files with different format, retrieving student record is complex.

4. Limited physical space storage.

5. Communication gap: Communication gap among various Department and Exams and Record prompt a lot of problems.

6. Incompleteness of information: The information recorded by some Department, even the exams and Record about student is incomplete because of the complexity involved in updating such information manually.

The researcher is hereby motivated to look at possible way of solving this problem by putting in place electronic record management system based on distributed system concept.

\section{Overview of the Method}

In realizing the purpose of this project, relevant information's are collected from personal observation, documented materials and consultation of various prospectuses. An object oriented model that is based on the object oriented paradigm is used in this research work along with Data Flow Diagram (DFD). Star networks topology is adopted for the distributed database system because of its low communication cost, moderate installation cost and the degree to which data can be accessed despite the occurrence of high link failures. In this project work majority protocol is used where each system maintains a Lock Manager whose function is to administer the lock and unlock requests for those records or data that are stored in that site.

Extensible mark-up language (XML) is the language of implementation of the proposed web-based distributed system, because records must be system and platformindependent and content dependent strutted query-template is used as the database engine. With these, new state-of-the-artelements can be added when needed in order to embraces institution-specific vocabulary.

\subsection{XML Path Language (XPath)}

XPath is a language for addressing parts of an XML document that utilizes a syntax that resembles hierarchical paths used to address parts of a filesystem or URL. XPath also supports the use of functions for interacting with the selected data from the document. It provides functions for the accessing information about document nodes as well as for the manipulation of strings, numbers and booleans. XPath is extensible with regards to functions which allow developers to add functions that manipulate the data retrieved by an XPath query to the library of functions available by default. XPath uses a compact, non-XML syntax in order to facilitate the use of XPath within URIs and XML attribute values (this is important for other W3C recommendations like XML schema and XSLT that use XPath within attributes). XPath operates on the abstract, logical structure of an XML document, rather than its surface syntax. XPath is designed to operate on a single XML document which it views as a tree of nodes and the values returned by an XPath query are considered conceptually to be nodes. The types of nodes that exist in the XPath data model of a document are text nodes, element nodes, attribute nodes, root nodes, namespace nodes, processing instruction nodes, and comment nodes.

XML is a W3C (World Wide Web Consortium) specification that defines a meta-language for describing data. In XML applications, data is described by surrounding it with customizable, text-based tags that give information about the data itself as well as its hierarchical structure.

Because XML syntax consists of text-based mark-up that describes the data being tagged, it is both applicationindependent and human readable. This simplicity and interoperability have helped XML achieve widespread acceptance and adoption as the standard for exchanging information between heterogeneous systems in a wide variety of applications, including Web services. XML forms the basis for all modern Web services, which use XML-based technologies to describe their interfaces and to encode their messages. WSDL, SOAP, and UDDI all use XML-based messaging that any machine can interpret.

However, the advent of XML means they can be integrated and made available electronically. This will lead to a considerable reduction in the risks associated with these, substances. XML can finally fulfill the promise of Electronic Data Interchange as a universal data interchange format not only suitable medium for conveying all kinds of information but it is also a data storage format. The scope of XML to be used as a standard for the interchange of structured and unstructured data goes far beyond the chemical industry alone. XML is ideally suited for the document-based exchange of information.

The development stage takes as its primary input the design elements described in the approved design document. For each design element, a set of one or more software artifacts will be produced. Software artifacts include but are not limited to menus, dialogs, data management forms, data reporting formats, and specialized procedures and functions. Appropriate test cases will be developed for each set of functionally related software artifacts, and an online help system will be developed to guide users in their interactions with the software. Figure 1 shows the stages involved in software development process while Figure 2 describes the database design. 


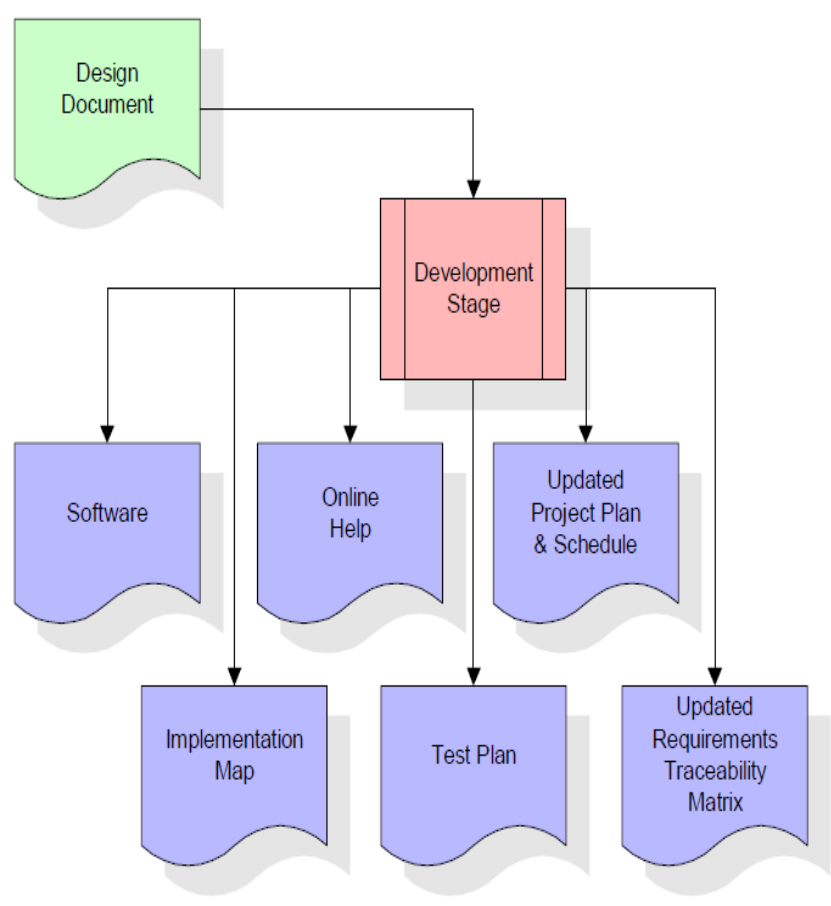

Figure1: Development Stage of the Software Process

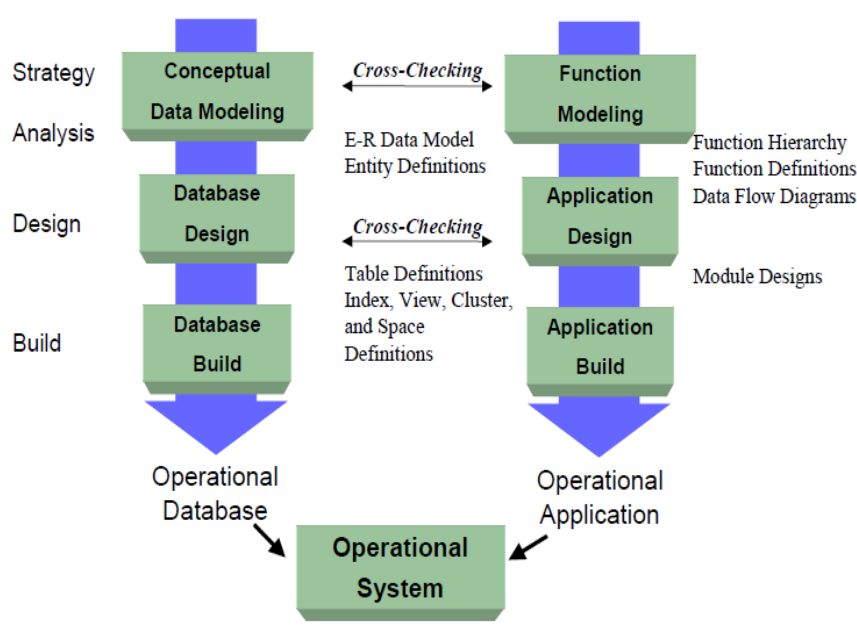

Figure 2: Database Design

\section{Results and Discussion}

Thus, the implementation of the program design is done using web based language (Extensible markup language-XML. The user is expected to supply the username and password before gaining access to the student records. This is a security measure put in place to checkmate unauthorized access to the student record database. Since the DSSR system is centrally available, the login information is available to staff and all other stakeholders involved in the use of the DSSR system with different access levels.
The DSSR is developed to allow for a number of operations on student records including search, retrieval and update. A page is dedicated for explaining the nature and content of the DSSR system. This system is developed to ensure that records are easily accessible, portable over mobile ends, flexible and easily transferred.

The basic information required to transfer student's information include matric number, surname, other names, sex, purpose of transfer, the sender and the recipient's sessions, phone number and the officer in charge. The user of the DSSR system is expected to fill the form and click the appropriate command button to transfer the student form.

The staff directory page is expected to enlist all registered users on the DSSR system from the various sections of the university ranging from registry, bursary to postgraduate school. The staff directory is designed to showcase the full name, department and email addresses of the registered users.

\section{Summary}

In applied database, most of the work done up to date has focused on building data warehouses for industries such as financial services, telecommunication utilities and manufacturing, little has been done on the application in the educational sector. This research investigates building a distributed system for exchanging of student records in academic environment with emphasis on tertiary institutions. It specifies Data Flow Diagram of the requirement specification, object-oriented requirement, the object-oriented model and an algorithm (Pseudocode) for the program design.

\section{Conclusion}

The research work is a web-based implementation using Extensible Markup Language (XML), PHP and mysql which provide an opportunity for institution specific vocabulary and mechanisms for addition of new state of the art element, which individual section of the institution can apply to meet its requirements and specific needs.

\section{Recommendation for Future Study}

Dataware-houses store huge amount of data, far beyond what has been the case previously, for tertiary institution, a Datamart which is a miniature Data warehouses can be constructed, this attempt will create opportunities for advancing the state of the art. Also the program design for the object-oriented model can be developed in later years.

\section{REFERENCES}

[1] Abraham S., Hency F. K., Sudarshan, S. (1997). Database System Concretes $3^{\text {rd }}$ Edition.

[2] Cartons, C., Peter, R. (2000). Database System Design, Implementation and Management $4^{\text {th }}$ Edition.

[3] Choongo, M. W. (1998). Justification for Setting up an archives at the University of Zambia: Problems and Prospects. African Journal of Library, Archives and Information Science, 8(2), 77 - 88.

[4] Currie, I. \& Klaaren, J. (2002). The promotion of Access to Information Act Commentary. Claredon (S. A): Siber INK.

[5] Djorka, J. \& Conneen, S. (1984). Records Management as an appraisal tool in College and University Archives (in 
Peace, N. E. (ed.) Archival Choices). Ottawa D. C.: Health and Company, $19-60$.

[6] Edward, S. \& McLeod, J. (2004). Is the Freedom of Information Act driving records management in further education colleges? Records management Journal, 14(1), $40-50$.

[7] Gold, G. (1995).How to set up and implement a record Management system, New York: American Management Association

[8] Kermoni, H. \& Wamukoya, J. (2000). Preparing for the management of electronic records at Moi University, Kenya: a case study. African Journal of Library, Archives and Information Science, 10(2), 125-138.

[9] Maher, W. (1992). The Management of college and university archives. London: Scarecrow.

[10] Mnjama, N. M. (2002). Managing university records. Journal of Eastern and Southern African Regional Branch of the International Council on Archives, 21, 32 -40 .

[11] Nwosu, C. O. (1993). Records and Information Management at the University of Nigeria, Nsuka. The Nigerian Archives, 4, 27 - 35.

[12] Pfleeger, S. L. (1997). Software Engineering Theory and Practice $2^{\text {nd }}$ Edition. Washington D.C.: Pearson Education.
[13] Procter, M. (2002). One size does not fit all: developing records management in higher education. Records Management Journal, 12(2), 48 - 54.

[14] Robek, M. F., Brown, G. F. \& Stephens, D. O. (1995). Information and Records Management: Document based Information System. New York: McGraw-Hill.

[15] Roy, F., Gabriel, K. \& Chen, A. (2010). Probablistic Quorum Sysyetms in Wireless AdHoc Networks, ACM Transactions on Computer Systems (TOCS), 28(3), doi = 10.1145/18413.18413.

[16] South Africa (2000). Promotion of Access to Information Act No. 2 of 2000. Republic of South Africa Government Gazette, 416(20852).

[17] Ugwunze, T. V. (1992). An examination of records management in the university of Lagos registry, African Journal of Library, Archives and Information Science, 2(1), 39 - 46.

[18] Uwaifo, O. O. (2004). Management use of records in Delta state University, Abraka, Nigeria, Record Management Journal, 14(2), 85 - 89.

[19] Wamukoya, J. (2000). Records and archives as a basis for good government: Implications and challenges for records managers and archivists in Africa. Records Management Journal, 10(1), 85 - 89.

[20] Wema, E. (2003). Problems of managing semi-active records in institutions of higher learning: the case of University of Dar ES Salaam. University of Dar ES Salaam Library Journal, 5(1), 46 - 56. 